\title{
The surgical management of chronic hypotony due to uveitis
}

\begin{abstract}
Purpose Evaluate surgery in chronic hypotony secondary to uveitis.

Method Retrospective analysis of six patients operated for chronic hypotony $(\leqslant 5 \mathrm{mmHg})$ of at least 1 month's duration. Surgery involved removal of all traction and membranes on the ciliary processes. Use of oil was limited to patients with atrophic ciliary processes.

Results The average postoperative follow-up was 24 months (12-43). The average pressure increase was $7 \mathrm{mmHg}$ at 6 months. Four of six uveitis patients had significantly increased vision.

Conclusion Improved vision, and a sustained pressure rise are possible in hypotonous uveitis. The presence of ciliary processes is necessary. However, they do not need to be intact.

Eye (2005) 19, 60-64. doi:10.1038/sj.eye.6701425
\end{abstract}

Published online 20 August 2004

Department of

Ophthalmology

Academic Medical Center University of Amsterdam Amsterdam

The Netherlands

Correspondence:

MD de Smet

Rm G2-217

Academic Medical Center University of Amsterdam

Meibergdreef 9

Amsterdam 1105 AZ

The Netherlands

Fax: + 31205669053

Tel: + 31205663455

E-mail:m.d.desmet@

amc.uva.nl

Received: 15 October 2003 Accepted: 28 November 2003

Published online: 20 August 2004
Keywords: hypotony; surgery; uveitis

\section{Introduction}

Hypotony can result from many aetiologies, with several mechanisms working in concert to reduce intraocular pressure. ${ }^{1,2}$ It is commonly seen in patients with a history of ocular trauma, previous vitreoretinal surgery, particularly if complicated by proliferative vitreoretinopathy, and in cases of long-standing uveitis. While mild hypotony is often transient and is of little consequence, a pressure below $4-6 \mathrm{mmHg}$ can have deleterious effects on ocular function and if sustained can lead to phthisis. ${ }^{1,3-6}$

Anterior vitreous traction on the ciliary processes is considered to be one of the mechanisms by which hypotony is induced in post-traumatic or postvitrectomy cases. ${ }^{7-10}$ In these cases, removing antero-posterior traction, and epiciliary membranes can lead to a
MD de Smet, F Gunning and R Feenstra

moderate increase in intraocular pressure. ${ }^{7,11,12}$ Either gas or silicone oil can be used to provide postoperative tamponade. With the use of gas, the pressure increase was sustained in $2 / 3$ of patients, while with oil, a modest increase was noted in above $90 \%$ of patients. Visual acuity results were similar in both groups, with the majority of patients having only a limited gain in acuity.

Hypotony resulting from ocular inflammation is observed in both the acute and chronic phase of disease. Hyperacute ocular inflammation can induce a significant drop in intraocular pressure, which usually resolves once the inflammatory episode is brought under control. ${ }^{1,4}$ This form of hypotony is likely mediated by the secretion of prostaglandins such as $\mathrm{PGF}_{2}-\alpha$, which increase uveoscleral outflow. ${ }^{13-15}$ Chronic uveitis can lead to the development of cyclitic membranes, which both increase outflow by placing traction on the ciliary processes, and decrease secretion by directly damaging the ciliary epithelium. ${ }^{5}$ With time, the hypotonous process can itself lead to further damage, including sclerosis and atrophy of ciliary processes. ${ }^{4,16}$ Medical treatment may be sufficient in early forms of inflammatory hypotony, but in the presence of a tractional detachment, surgical release of the tractional forces has been advocated. It was shown to improve intraocular pressure in a case of sarcoid uveitis, as well as in a case of juvenile chronic arthritis. ${ }^{17}$

In the current study, we investigated the value of surgical management of inflammatory hypotony in a larger group of patients.

\section{Methods}

Through a retrospective chart review, patients who had undergone surgery to treat hypotony in the Ophthalmology department of the Academic Medical Center, University of 
Table 1 Patient demographics

\begin{tabular}{lcccccc}
\hline $\begin{array}{l}\text { Patient } \\
\text { number }\end{array}$ & $\begin{array}{c}\text { Age } \\
\text { (years) }\end{array}$ & Sex & $\begin{array}{c}\text { Duration of } \\
\text { hypotony }\end{array}$ & $\begin{array}{c}\text { Duration of } \\
\text { follow-up (months) }\end{array}$ & $\begin{array}{c}\text { Number of prior } \\
\text { surgeries }\end{array}$ & Primary diagnosis \\
\hline 1 & 44 & F & 2 & 17 & 1 & Intermediate U \\
2 & 14 & F & 3 & 8 & 0 & Sarcoidosis \\
3 & 10 & M & 2 & 38 & 2 & Sarcoidosis \\
4 & 21 & F & 3 & 43 & 2 & Sarcoidosis \\
5 & 50 & M & $>12$ & 7 & 1 & Reiter's syndrome \\
6 & 69 & F & $>12$ & Idiopathic U \\
\hline
\end{tabular}

aCorresponds to the minimal documented duration either in our clinic or elsewhere.

Amsterdam from January 1997 to September 2001 were identified. Patient demographics and characteristics are summarized in Table 1. Only patients who were operated upon with an intraocular pressure of $5 \mathrm{mmHg}$ or less for at least a month's duration, and documented on at least two separate visits were included in the study. The last recorded intraocular pressure prior to surgery is reported. Visual acuity was measured at each visit. The best-corrected visions are reported in this series.

During the initial evaluation period, patients with a diagnosis of intraocular inflammation were more intensively treated with either 1 to 2 subtenon's injection of triamcinolone, or by raising the level of systemic steroids by at least $0.5 \mathrm{mg} / \mathrm{kg} /$ day. Visual acuity, intraocular pressure, cell, and flare were carefully monitored for signs of improvement over the following month. As a pre-requisite for surgery, eyes were required not to show sustained improvement with medical treatment. In particular, the intraocular pressure on two occasions while under treatment remained below or equal to $5 \mathrm{mmHg}$. Several patients were sent for ultrasound biomicroscopy of their ciliary body for any evidence of epiciliary tissue, ciliary body detachment with supraciliary effusion, traction on the ciliary processes, and, in particular for the absence of complete atrophy of the ciliary body. In the perioperative period, intense anti-inflammatory therapy was maintained. At the time of surgery, a periocular or intraocular injection of triamcinolone was given. Anti-inflammatory medications were slowly tapered in the postoperative period based upon the observed level of intraocular inflammation.

All patients were carefully examined at the time of surgery to determine the state of the ciliary processes. This was judged in terms of the severity and extent of epiciliary proliferations, the presence of anterior PVR (defined as the presence of adherent vitreous strands and/or sheet-like membranes extending from the region of the vitreous base anteriorly to attach to the ciliary body, posterior surface of the iris, or pupillary margin), and the extent and severity of ciliary process atrophy (seen as total absence, sclerotic processes (crest alone, or including the base of the ciliary process), or processes of normal appearance).

A conventional three-port pars plana technique was performed in all cases, with the sclerotomies placed $3 \mathrm{~mm}$ posterior to the limbus, and the superior two sclerotomies positioned in the 3 and 9 o'clock meridians to allow for better visualization and manipulation of the superior peripheral retina, and ciliary body region. Lens capsule, pupillary membranes, and residual lens material were removed first. Any remaining vitreous present adjacent to the vitreous base was shaved using low suction, and a high cut rate. The ciliary processes were assessed as indicated above. In several cases, membranes were first dissected away, before the ciliary processes could be assessed. Epiciliary tissue was incised using an MVR blade under direct visualization through the pupil. If visualization was deemed to be insufficient, the endoilluminator probe was held externally by the assistant at the edge of the limbus, directing the light beam from an angle situated $180^{\circ}$ opposite to the tissue being manipulated. Extensive external indentation of the pars plana region allowed adequate visualization of the peripheral retina, and ciliary body region.

Once the ciliary processes were exposed, the epiciliary tissue was carefully stripped from the surface of the processes using microscissors, a bent MVR blade, or dissector combined with a microforceps. This approach minimized traction on the ciliary processes themselves. If the underlying processes appeared to be of normal size with minimal fibrosis in roughly $1 / 4$ of the eye's circumference, no oil was injected in the eye at the completion of the procedure.

\section{Results}

Six uveitis patients were identified as meeting the inclusion criteria defined in the methods section (Table 1). Two patients were male, and four female, with a mean age of 35 years (range 10-69 years). Hypotony was present from 1 month to several years. In both patients 
whose hypotony was present for more than 1 year, a symptomatic visual drop was noted in the previous 2 to 3 months. The patient with intermediate uveitis had a limited peripheral retinal detachment and hypotony. The detachment extended over 3 clock hours peripherally and reached the arcade posteriorly. Prominent anterior vitreous traction was seen to the posterior lens surface over $1 / 2$ of the circumference. This was removed under endoscopic visualization, allowing the intraocular lens to remain in situ. As shown in Table 1, some patients had had prior surgery consisting of either cataract extraction, and/or pars plana vitrectomy with IOL insertion or removal. None of these patients had cyclodestructive procedures, nor extensive vitreo-retinal surgery. None had undergone a retinotomy, nor had silicone oil been injected in their eye before developing hypotony.

Preoperative assessment using the UBM showed the presence of a supraciliary effusion in two patients, and traction on the ciliary processes in one (Figure 1). Thick epiciliary tissue prevented visualization of the ciliary

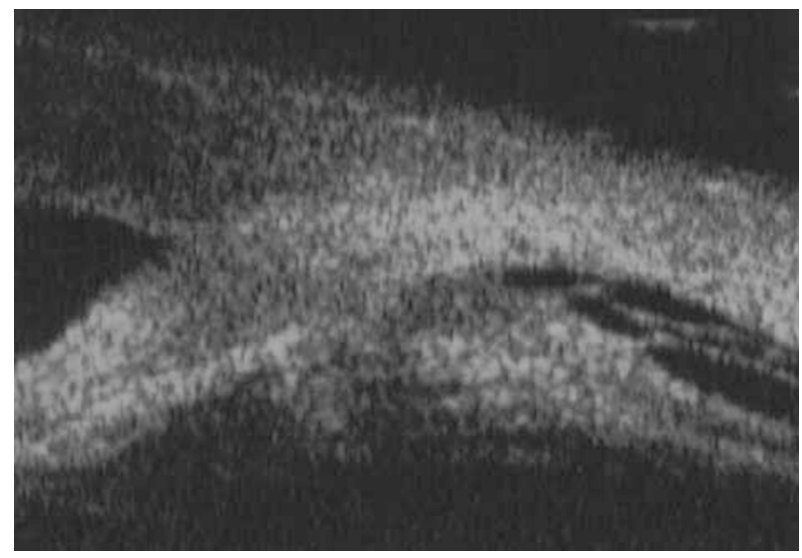

Figure 1 UBM showing ciliary body detachment in case number 5 . There is also evidence of vitreous condensation on the posterior iris surface. processes in two patients. In one, the membranes extended onto the posterior surface of the iris. UBM was not performed in two uveitis patients. Standard ultrasound did not show any abnormality.

At the time of surgery, the condition of the ciliary processes was carefully assessed (Table 2). Some degree of epiciliary tissue extending onto the iris surface was observed in one uveitis patient with long-standing hypotony. Some degree of ciliary sclerosis was noted in two patients. In one the process was severe, involving most processes (patient 6). Silicone oil was injected in her eye at the end of the procedure.

The postoperative course was highly variable. A moderate degree of inflammation with increased flare was noted in all eyes. Two uveitis patients developed a vitreous haemorrhage that required 2-3 months to clear. The postoperative rise in intraocular pressure occurred at a variable rate. It was often not present in the immediate postoperative period, but appeared within the first postoperative month. In one patient with sarcoidosis, a significant pressure rise developed after tapering antisuppressive medication (Table 3). Visual acuity results are reported in Table 4. Significant visual acuity gains were achieved in four of the six uveitis patients. In one, the visual gain was limited due to on-going inflammation and the development of band keratopathy.

Table 3 Intraocular pressure results $(\mathrm{mmHg})$

\begin{tabular}{lcrccc}
\hline Patient no. & Pre-op & 1 week & 1 month & 6 months & $1+$ year \\
\hline 1 & 1 & 8 & 12 & 15 & 15 \\
2 & 2 & 8 & 12 & 14 & 10 \\
3 & 2 & 14 & 14 & 27 & 20 \\
4 & 0 & 5 & 3 & 4 & 4 \\
5 & 0 & 4 & 6 & 7 & 8 \\
6 & 2 & 7 & 7 & 8 & 4 \\
\hline
\end{tabular}

Table 2 Surgical findings and procedure

\begin{tabular}{|c|c|c|c|c|c|}
\hline $\begin{array}{l}\text { Patient } \\
\text { no. }\end{array}$ & $\begin{array}{l}\text { Retina } \\
\text { status }^{\mathrm{a}}\end{array}$ & $\begin{array}{l}\text { Size of } \\
\text { processes }\end{array}$ & $\begin{array}{l}\text { Appearance } \\
\text { of processes }\end{array}$ & Nature of epiretinal tissue & Procedure \\
\hline 1 & RD-3 & $\mathrm{N}$ & $\mathrm{N}$ capsule & anterior proliferation to IOL + Endo $\mathrm{C}_{3} \mathrm{~F}_{8}$ & PPV CBP \\
\hline 2 & $\mathrm{~F}$ & $\mathrm{~N}$ & $\mathrm{~N}$ & Capsular membrane traction minimal epiciliary tissue & PPV PPL CBP \\
\hline 3 & $\mathrm{~F}$ & N6 D6 & N6 SF6 & $\begin{array}{l}\text { Thick epiretinal membrane underlying processes not } \\
\text { visible extending to posterior iris }\end{array}$ & $\begin{array}{l}\text { PPV CBP Rem } \\
\text { IOL }\end{array}$ \\
\hline 4 & $\mathrm{~F}$ & $\mathrm{~N}$ & $\mathrm{~N}$ & Traction to posterior capsule & PPV CBP \\
\hline 5 & $\mathrm{~F}$ & $\mathrm{~N}$ & $\mathrm{~N}$ & $\begin{array}{l}\text { Thick epiciliary membrane underlying processes not } \\
\text { visible membrane extending to posterior iris }\end{array}$ & PPV CBP \\
\hline 6 & $\mathrm{~F}$ MH & D8 A4 & SF12 BF10 & Moderate traction from vit base & PPV CBP SiO \\
\hline
\end{tabular}

aRetinal status: F—flat, RDX — retinal detachment ( $\mathrm{X}$ clock hours), MH—macular hole.Process size: N—normal, DX—decreased size (X clock hours), A — atrophic.Process appearance: N—normal, SFX- superficial fibrosis ( $\mathrm{X}$ clock hours), BF—base fibrosis ( $\mathrm{X}$ clock hours).Procedure: CBP — ciliary body peel; Endo - endoscopy; MP- epiretinal membrane peel; PPL — pars plana lentectomy; PPV- plana vitrectomy; Rem IOL — removal of intraocular lens; $\mathrm{SiO}$ - silicone oil. 
Table 4 Visual acuity results

\begin{tabular}{lcccc}
\hline $\begin{array}{l}\text { Patient } \\
\text { no. }\end{array}$ & Pre-op & $\begin{array}{c}\text { 1-3 month } \\
\text { visit }\end{array}$ & Last visit & $\begin{array}{c}\text { Follow-up } \\
\text { (months) }\end{array}$ \\
\hline 1 & CF $^{\mathrm{a}}$ & $20 / 50$ & $20 / 50$ & 17 \\
2 & $\mathrm{HM} \mathrm{1m}$ & $20 / 60$ & $20 / 30$ & 12 \\
3 & $\mathrm{CF}$ & $20 / 200$ & $\mathrm{CF}^{\mathrm{b}}$ & 38 \\
4 & $\mathrm{CF}$ & $\mathrm{CF}$ & $20 / 80^{\mathrm{c}}$ & 24 \\
5 & $20 / 100$ & $\mathrm{CF}$ & $20 / 20$ & 43 \\
6 & $\mathrm{HM} \mathrm{1m}$ & $\mathrm{CF} 1 \mathrm{~m}$ & $\mathrm{CF} 2 \mathrm{~m}$ & 12 \\
\hline
\end{tabular}

a Abbreviations: $\mathrm{CF}$ - count fingers, $\mathrm{HM}$ - hand motion.

bPatient has a central band keratopathy. Maximal vision was 20/100.

cPatient noted to have capsular opacity + epiretinal membrane.

\section{Discussion}

Within the realm of inflammatory ocular diseases, a prolonged lowered pressure can occur on the basis of ciliary body inflammation or as a consequence of tractional forces on the ciliary processes, both leading to decreased aqueous production. ${ }^{4}$ Ocular signs can be of some utility in differentiating the two, as acute hypotony is often associated with inflammation (cell and flare) in the anterior chamber and/or the peripheral vitreous, while the latter is often present in a relatively quiet eye (although hypotony can itself cause increased flare in the absence of cells in the anterior chamber). ${ }^{4}$ To ensure timely management, a stepwise approach to inflammatory hypotony can be of use in guiding care for these patients.

First, one has to be certain that ocular inflammation is brought under control. Whatever the anti-inflammatory cocktail being used by an individual patient, it should be raised sufficiently to allow resolution of inflammatory hypotony if present. This is more likely to be present in hypotony of recent onset and when there is a prominent inflammatory response. If effective, the antiinflammatory cocktail can be slowly tapered based on the patient's response. With adequate anti-inflammatory therapy, some degree of response should be visible within 2-3 months. This was not observed in any of the patients we treated.

If no response is observed with anti-inflammatory agents, the further course will be dependent on the state of the ciliary body. The presence of a detached ciliary body and the absence of ciliary process atrophy suggest a better surgical prognosis. A careful preoperative assessment of the ciliary body should be carried out preferably with the use of a UBM or similar device. This evaluation can also help to identify the location and thickness of epiciliary membranes, and thus help in surgical planning. In patients where ciliary processes are absent, and it is clear that they are not hidden by epiciliary membranes, surgery alone is unlikely to lead to a significant rise in pressure or vision. Some authors have advocated the use of periocular, or systemic steroids, but the efficacy of these modalities is limited. ${ }^{18}$ Recently, intraocular triamcinolone or the use of topical ibopamine have been proposed as an alternative, both are dependent on residual ciliary body function. ${ }^{19,20}$ Both also require continuous treatment, or repeated injection.

If surgery is chosen, or atrophy is noted at the time of surgery, silicone oil may prevent the development of phthisis. It can lead to a moderate increase in pressure. ${ }^{21}$

At the time of surgery, it is necessary to remove carefully all peripheral vitreous gel, and all epiciliary tissue over $360^{\circ}$. Removal of any residual lens or capsular support is also performed if it is contributing to the traction on the ciliary processes. The epiciliary tissue is removed using a bimanual technique to minimize traction on the ciliary body epithelium, as this procedure can lead to the unnecessary removal of ciliary epithelium as we and others have noted in surgical specimens. ${ }^{7}$

The ciliary body is then carefully examined by deep indentation or using an endoscopic viewing system. Normal processes will have well-defined crypts, a slightly corrugated appearance, and have a deep brown colour. In a dysfunctional ciliary body, processes can be completely absent, in which case a white fibrotic plaque with a variable degree of pigmentation is left behind. Partial ciliary body dysfunction can be identified as fibrosis (whitening) most often beginning on the top of the processes, extending only later to the crypts. We have attempted to classify the appearance of the ciliary processes in our patients based on the above description. As noted in Table 3, the appearance can vary in different parts of the eye. In the presence of normal-appearing ciliary processes, or with fibrosis limited to the crests of the processes, no further surgery is required. In the presence of significant ciliary process atrophy, silicone oil is advisable.

Perioperative anti-inflammatory control is also important and should be carefully monitored. Intraocular inflammation and fibrin formation is frequently observed following surgery in hypotonous eyes. ${ }^{7}$ Reducing preoperative inflammation as suggested in step one, topped by giving additional periocular or intraocular steroids at the time of surgery, can help to reduce postoperative fibrin formation. Reducing postoperative fibrin will reduce the risk of recurrent epiretinal and epiciliary membrane formation, and thus reduces the risk of a recurrent hypotony. ${ }^{11,22}$ Our uveitis patients did particularly well with regard to intraocular pressure and vision. Our own results in PVR or ocular infection patients have led to only limited improvement in keeping with previously published series. ${ }^{7,8,11}$

In an experimental hypotony model, the development of an epiciliary membrane was associated with a progressive loss of nonpigmented and pigmented 
epithelium over a period of several weeks. ${ }^{16}$ Hypotony developed in parallel with this tissue loss. With longstanding hypotony, progressive atrophy of the ciliary processes can occur, reducing the likelihood of a functional recovery. This was probably the case in our sixth patient, who only experienced a transient increase in pressure following surgery, and in whom the processes were noted to be atrophic at the time of surgery. She had uveitis for several years prior to her arrival in our clinic. Young patients appear to carry a particularly favourable prognosis. Following surgery, they recovered normal intraocular pressure and significant vision. However, compliance with postoperative anti-inflammatory therapy may be a problem in this patient population, as was the case in patient 2.

In conclusion, certain cases of hypotony due to uveitis are amenable to surgical therapy, but should be carried out prior to the development of irreversible ciliary process damage. When operated upon in a timely fashion, sustained gains in pressure and vision are possible. However, for patients with ciliary process atrophy, or hypotony from other causes, the currently available surgical approaches do not appear to present much benefit, except for the avoidance of phthisis bulbi. Other approaches will be required in these patients.

\section{References}

1 Schubert HD. Postsurgical hypotony: relationship to fistulization, inflammation, chorioretinal lesions, and the vitreous. Surv Ophthalmol 1996; 41: 97-125.

2 Brubaker RF, Pederson JE. Ciliochoroidal detachment. Surv Ophthalmol 1983; 27: 281-289.

3 Pederson JE. Hypotony. In: Jaeger EA (ed). Duane's Clinical Ophthalmology, Vol. 3. Lippincott-Raven: Philadelphia, 1999, pp 1-8.

4 Tran VT, Mermoud A, Herbort CP. Appraisal and management of ocular hypotony and glaucoma associated with uveitis. Int Ophthalmol Clin 2000; 40: 175-203.

5 Pederson JE. Ocular hypotony. Trans Ophthalmol Soc UK 1986; 105: 220-226.

6 Minckler DS, Tso MOM, Zimmerman LE. A light microscopic, autoradiographic study of axoplasmic transport in the optic nerve head during ocular hypotony, increased intraocular pressure, and papilledema. Am J Ophthalmol 1976; 82: 741-756.
7 O'Connell SR, Majji AB, Humayun MS, de Juan Jr E. The surgical management of hypotony. Ophthalmol 2000; 107: 318-323.

8 Lewis H, Aaberg TM. Anterior proliferative vitreoretinopathy. Am J Ophthalmol 1988; 105: 277-284.

9 Lewis H, Aaberg TM. Causes of failure after repeat vitreoretinal surgery for recurrent proliferative vitreoretinopathy. Am J Ophthalmol 1991; 111: 15-19.

10 Barr CC, Lai MY, Lean JS, Linton KLP, Trese M, Abrams G et al. Postoperative intraocular pressure abnormalities in the silicone study. Silicone Study Report 4. Ophthalmol 1993; 100: 1629-1635.

11 Lewis H, Verdaguer JI. Surgical treatment for chronic hypotony and anterior proliferative vitreoretinopathy. Am J Ophthalmol 1996; 122: 228-235.

12 Zarbin MA, Michels RG, Green WR. Dissection of epiciliary tissue to treat chronic hypotony after surgery for retinal detachment with proliferative vitreoretinopathy. Retina 1991; 11: 208-213.

13 Herbort CP, Okumura A, Mochizuki M. Endotoxin induced uveitis in the rat: a study of the role of inflammation mediators. Graefe's Arch Clin Exp Ophthalmol 1988; 226: 553-556.

14 Mermoud A, Baervekdt G, Minckler DS, Rao NA. Prostaglandines E2 et F2-alpha au cours du glaucome uvéitique chez le rat Lewis. Klin Monatsbl Augenheilk 1995; 206: 409-412.

15 Toris C, Pederson JE. Aqueous humor dynamics in experimental iridocyclitis. Invest Ophthalmol Visual Sci 1987; 28: 477-481.

16 Kim HC, Hayashi A, Shalash A, de Juan Jr E. A model of chronic hypotony in the rabbit. Graefe's Arch Clin Exp Ophthalmol 1998; 236: 69-74.

17 Chan CC, Wetzig RP, Palestine AG, Kuwabara T, Nusenblatt RB. Immunohistopathology of ocular sarcoidosis. Report of a case and discussion of immunopathogenesis. Arch Ophthalmol 1987; 105: 1398-1402.

18 Pederson JE, Mac Lellan HM. Medical therapy for experimental hypotony. Arch Ophthalmol 1982; 100: 815-817.

19 Jonas JB, Hayler JK, Panda-Jones S. Intravitreal injection of crystalline cortisone as treatment of pre-phthisical ocular hypotony. Graefe's Arch Clin Exp Ophthalmol 2001; 239: 464-465.

20 Pivetti-Pezzi P, Da Dalt S, La Cava M, Pinca M, de Gregorio F, Virno M. Ibopamine treatment in chronic hypotony secondary to long-lasting uveitis. A case report. Eur J Ophthalmol 2000; 10: 332-334.

21 Morse LS, McCuen BWI. The use of silicone oil in uveitis and hypotony. Retina 1991; 11: 399-404.

22 Vidauri-Leal JS, Glaser BM. Effect of fibrin on morphologic characteristics of retinal pigment epithelial cells. Arch Ophthalmol 1984; 102: 1376-1379. 